\title{
CHANGES IN SELECTED MORPHOLOGICAL PARAMETERS AND BODY COMPOSITION, AS WELL AS MEAN BODY SURFACE TEMPERATURE ASSESSED BY THERMAL IMAGING, IN WOMEN AFTER ABDOMINAL LIPOSUCTION
}

\author{
Monika Chudecka, ${ }^{1, A, B, C, D}$ Andrzej Dmytrzak, ${ }^{2, B}$ Anna Lubkowska, A, D \\ ${ }^{1}$ Department of Human Functional Anatomy and Biometry, Faculty of Physical Culture and Health Promotion, University of Szczecin, Poland \\ ${ }^{2}$ Aesthetic Med Andrzej Dmytrzak, Poland \\ ${ }^{3}$ Department of Functional Diagnostics and Physical Medicine, Faculty of Health Sciences, Pomeranian Medical University in Szczecin, Poland

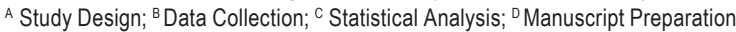

\author{
Address for corpespondence: \\ Anna Lubkowska \\ Pomeranian Medical University in Szczecin, Faculty of Health Sciences, Department of Functional Diagnostics and Physical Medicine \\ Żołnierska 54, 71-210 Szczecin, Poland \\ E-mail: AnnaLubkowska@gmail.com
}

\begin{abstract}
Ahstract. The aim of this study was to assess changes in selected morphological parameters and body composition, as well as in the mean body surface temperature determined by thermal imaging, in women after abdominal liposuction. As abdominal tissue edema and inflammation often persist after liposuction, body composition and surface temperatures were analyzed 3 months after surgery, during a control visit to the clinic. The 12-week delay allowed to eliminate the confounding effects of post-surgical inflammation on our results. We found a statistically significant decrease in all the analyzed morphological parameters and a change in body composition. A reduction in the subcutaneous fat tissue in the abdomen resulted in upward trends in the surface temperature of most of the analyzed areas, with a highly significant increase in the abdominal area. These studies can be considered pioneering and significant in confirming the role of subcutaneous fat as a factor regulating the body surface temperature.
\end{abstract}

Key WOPld: liposuction, body component, fat, body temperature, thermography

\section{Introduction}

Liposuction involves breaking up and removing the excessively accumulated subcutaneous fat in order to correct the shape and contours of one or several body areas. During the surgery, the excess fat is removed from a selected area, leaving a $1 \mathrm{~cm}$ layer of fat under the skin; in this way relatively large amounts of subcutaneous adipose tissue may be removed from the body. (Matarasso, Hutchinson, 2001; The American..., 2002) This method can be used to model the abdomen, buttocks, thighs, knees, upper parts of the arms, chin, cheeks and neck. 
The most common arguments in favor of abdominal liposuction are the ineffectiveness of diet and exercise in reducing excess body fat and disproportionate physique. The full effect of the surgery is visible after 2-3 months. However, little is known about the physiological, biochemical or metabolic effects of liposuction. During the relatively long procedure, patients are exposed to anesthesia, exchange of fluids and infusion of high doses of epinephrine and lidocaine.

One of the greatest perioperative complications is embolism, resulting from the penetration of the broken-up fat through the blood vessels to lungs or brain, and skin necrosis. Plastic surgeons argue, however, that routine liposuction has very low risk of perioperative complications and therefore is considered to be generally harmless. However, due to the fact that the subcutaneous adipose tissue has nutritional and thermodynamic metabolic functions, proportional to its absolute amount and distribution, it is possible that the removal of subcutaneous adipose tissue may adversely affect metabolism. This is also due to the bidirectional interaction between adipose tissue - a metabolically active organ - and other tissues (Matarasso, Kim, Kral, 1998)

Liposuction is associated with inflammation and change in the flow of heat, which result in a large temperature gradient between the area of surgery and its immediate surroundings. This may lead to thermoregulatory disturbances and changes in the body surface temperature. Therefore, we aimed to determine the changes in some morphological parameters and body composition, and changes in the mean body surface temperature, 3 months after liposuction, compared to baseline levels before the surgery.

The aim of the study was to assess changes in selected morphological parameters and body composition, as well as changes in the mean surface temperatures of the body by thermal imaging, in women after abdominal liposuction.

\section{Material and methods}

The study was conducted at the Aesthetic Med Andrzej Dmytrzak Plastic Surgery Clinic in Szczecin, Poland, in 2013-2014. It involved 10 women aged 23-50 years ( $M=39.4, S d=9.5)$, qualified for abdominal liposuction. The amount of fat removed during the surgery ranged from 2.5 to 5.0 liters $(M=3.4 L ; S D=0.9)$. The tests were performed before the surgery and three months after surgery, during the control visit. Each of the participants gave written consent before participating in the study, in accordance with the Declaration of Helsinki.

The study was approved by the Bioethics Committee of the Pomeranian Medical University. ThermaCAM SC500 Flir Systems thermal imaging camera was used, with thermal sensitivity of $<0.1^{\circ} \mathrm{C}$, and with the use of AGEMA software. Computer imaging analysis was used to prepare the thermograms of the chest, abdomen, back, front and rear surfaces of arms, forearms and hands, as well as the front and back surfaces of thighs and shanks.

Each time the we recorded maximum, mean and minimum temperatures in the designated areas. Analysis concerned mean temperatures $\left(T_{\text {mean }}\right)$ of the designated areas of the body. The tests were always performed in accordance with the standards of the European Thermological Society, in a room with an area of $12 \mathrm{~m}^{2}$, humidity of $55-60 \%$ and temperature $25^{\circ} \mathrm{C}$. The patients were given the recommended acclimatization time of 20 minutes; they remained in the room only in underwear so that the heat exchange with the environment stabilized before the infrared test. We assumed the emissivity of the skin to be 0.98 . Photos were taken from a distance of $3 \mathrm{~m}$, with subjects in a standing position (Fujimasa, 1995; Żuber, Jung, 1997; Bauer, Dereń, 2014). 
We also performed anthropometric measurements in accordance with the rules adopted after Drozdowski (1998). The measurement of body composition used the bioimpedance method and the Jawon Medical X-Scan Plus body composition analyzer. We determined waist circumference (WC) [cm], body weight [kg], percentage of body fat (PBF), visceral fat mass *VFM) [kg], subcutaneous fat mass (SFM) [kg]), percentage of the total body fat (TF) and body mass index (BMI) $\left(\left[\mathrm{kg} / \mathrm{m}^{2}\right)\right]$.

\section{Analysis}

Table 1 shows the means (M) and standard deviations (Sd) for body weight, abdominal circumference, and PBF, VFM, SFM, TF and BMI before liposuction surgery and 3 months after surgery, during the control test. We calculated the significance of differences (dependent Student-t test) at $p<0.05$.

All the women showed a decrease in the value of all the analyzed morphological parameters and a change in body composition 3 months after liposuction. Body weight of the women fell significantly, on average by $3.2 \pm 0.86$ $\mathrm{kg}$, accompanied by the expected reduction in waist circumference of $3.4 \pm 2.0 \mathrm{~cm}$.

Liposuction decreased body weight and body-mass index, due to a marked decrease in total body fat (2.5 $\pm 1.57 \mathrm{~kg}$ ), especially in subcutaneous fat mass, from $19.7 \pm 7.8$ to $17.6 \pm 6.6 \mathrm{~kg}$, but also in visceral fat mass from $2.6 \pm 1.3$ to $2.3 \pm 1.3 \mathrm{~kg}$, although the change in the visceral fat was the smallest.

Table 1. Arithmetic means, standard deviations and the results of the Student's t-test for the morphological parameters and body composition of women before and 3 months after liposuction

\begin{tabular}{|c|c|c|c|c|c|c|}
\hline & \\
\hline & M1 & SD1 & M2 & SD2 & $\Delta \mathrm{M} 1-\mathrm{M} 2 \pm \mathrm{SD}$ & $\begin{array}{c}p \text { value } \\
\text { in the Student's } \\
\text { t-test }\end{array}$ \\
\hline Age & 39.4 & 9.5 & - & - & - & - \\
\hline Body weight [kg] & 70.3 & 11.4 & 67.0 & 10.4 & $3.2 \pm 0.86$ & $<0.0001$ \\
\hline Weist Circumference [cm] & 86.3 & 9.5 & 83.0 & 8.1 & $3.4 \pm 2.00$ & 0.0007 \\
\hline BMI $\left[\mathrm{kg} / \mathrm{m}^{2}\right]$ & 25.4 & 2.3 & 24.4 & 2.1 & $1.3 \pm 0.26$ & $<0.0001$ \\
\hline PBF [\%] & 30.7 & 5.2 & 28.0 & 4.5 & $2.5 \pm 1.57$ & 0.0009 \\
\hline VFM [kg] & 2.6 & 1.3 & 2.3 & 1.3 & $0.3 \pm 0.23$ & 0.0018 \\
\hline SFM [kg] & 19.7 & 7.8 & 17.6 & 6.6 & $2.1 \pm 1.49$ & 0.0022 \\
\hline TF [\%] & 22.1 & 4.5 & 20.6 & 3.8 & $1.5 \pm 0.94$ & 0.0010 \\
\hline
\end{tabular}

$M_{1}$ - arithmetic mean before surgery.

$\mathrm{M}_{2}$ - arithmetic mean three months after liposuction.

Table 2 summarizes the values of arithmetic means and standard deviations and the results of the Student t-test for the analyzed body surface temperatures of women before surgery and 3 months after liposuction. It shows a statistically significant increase in temperature ( $\left.T_{\text {mean }}\right)$ after the liposuction only on the surface of the abdomen, i.e. the area from which a significant amount of fat was surgically removed. 
Table 2. Arithmetic means, standard deviations and the results of the Student's t-test for surface temperatures of selected areas of the body before and 3 months after liposuction

\begin{tabular}{|c|c|c|c|c|c|c|}
\hline & \multirow[b]{2}{*}{ M1 } & \multirow[b]{2}{*}{$\mathrm{SD} 1$} & \multirow[b]{2}{*}{ M2 } & \multirow[b]{2}{*}{ SD2 } & \multirow[b]{2}{*}{$\Delta \mathrm{M} 1-\mathrm{M} 2 \pm \mathrm{SD}$} & \multirow[b]{2}{*}{$\begin{array}{c}p \text { value } \\
\text { in the Student's } \\
\text { t-test }\end{array}$} \\
\hline & & & & & & \\
\hline Chest & 34.1 & 0.6 & 34.3 & 0.7 & $0.1 \pm 0.24$ & 0.13 \\
\hline Back Upper & 33.9 & 0.8 & 34.1 & 0.5 & $-0.2 \pm 035$ & 0.21 \\
\hline Arm,Forearm front & 32.6 & 0.6 & 32.8 & 0.6 & $-0.2 \pm 019$ & 0.26 \\
\hline Arm,Forearm back & 32.1 & 0.3 & 32.2 & 0.4 & $-0.1 \pm 022$ & 0.32 \\
\hline Hand front & 31.9 & 0.6 & 31.7 & 0.7 & $0.2 \pm 0.52$ & 0.24 \\
\hline Hand back & 31.6 & 0.5 & 31.4 & 0.5 & $0.2 \pm 0.48$ & 0.19 \\
\hline Abdomen & 33.5 & 0.8 & 34.0 & 1.0 & $0.8 \pm 0.31$ & 0.0003 \\
\hline Back Lower & 33.7 & 0.8 & 33.9 & 0.7 & $0.3 \pm 0.17$ & 0.22 \\
\hline Thigh front & 31.7 & 0.4 & 31.7 & 0.3 & $0 \pm 0.26$ & 0.76 \\
\hline Thigh back & 31.2 & 0.5 & 31.0 & 0.4 & $0.2 \pm 0.41$ & 0.43 \\
\hline Shank front & 31.3 & 0.3 & 31.3 & 0.2 & $0 \pm 0.15$ & 0.89 \\
\hline Shank back & 31.3 & 0.4 & 31.2 & 0.3 & 0.0 & 0.80 \\
\hline
\end{tabular}

$\mathrm{M}_{1}$ - arithmetic mean before surgery.

$\mathrm{M}_{2}$ - arithmetic mean three months after liposuction.

\section{Discussion}

This study is part of the project on the changes in the bodies of women following abdominal liposuction. Its aim was to determine changes in selected morphological parameters and body composition, and in the mean temperatures of selected areas of the body surface, taking into account local differences between those areas in healthy subjects with normal weight. Morphological parameters included weight, BMI, waist circumference, while body composition included lean body mass, body fat percentage, visceral fat mass, subcutaneous fat mass and percentage of body fat in the trunk.

Despite the surgeon's efforts to achieve technical perfection and maximum safety, each liposuction surgery leads to the destruction of some of the blood vessels supplying the skin, and damage to the cutaneous innervation. The regeneration of skin innervation and some other adverse changes may persist for some time. In this study, no serious complications occurred in any subject following liposuction surgery, and all were able to return to their usual lifestyle within one week after liposuction. Because abdominal tissue edema and inflammation can occur for a long time after liposuction, body compositions and surface temperatures were determined 3 months after the surgery, during a control visit to the clinic. The 12-week delay allowed to eliminate the confounding effects of post-surgical inflammation on our results.

Nearly $65-70 \%$ of body fat accumulates in the subcutaneous tissue. Patients with central obesity accumulate both visceral and abdominal subcutaneous fat. Subcutaneous adipose tissue is a typical anabolic organ with a large capacity. Chronic excessive supply of energy results in the subcutaneous adipocyte hypertrophy and increased number of adipocytes (Unger, 2003).

Recently, liposuction has been the subject of studies that concerned the durability of its effect and the potential impact on metabolism. Authors often present divergent opinions, and some find no metabolically favorable effect, 
as only part of hypertrophic adipocytes are removed during the surgery, while the remaining hypertrophic visceral adipocytes still affect the body's insulin resistance (Simka, 2007).

As expected, in our research liposuction in the abdominal region resulted in a reduction in abdominal circumference. Changes that occurred in the composition of the body related to both subcutaneous and visceral fat, and additionally the decrease in measured fat mass, were consistent with the amount of fat aspirated during liposuction (3.4 $\pm 0.9 \mathrm{~L})$. The relationship between the endocrine activity of the adipose tissue and function of the thyroid hormone justified by their close relationship with the control of energy balance and, above all, insulating function of fat tissue, led us to hypothesize on the possibility of changes in the surface temperature of the body following liposuction surgery, which could be estimated through thermography.

Some authors have reported that subcutaneous fat layer has some influence on the skin temperature. Significant correlation between thigh skin temperature and thigh skinfold thickness $(r=-0.488, p=0.020)$ over rectus femoral muscle have been observed (Bandeira, Moura, Souza, Nohama, Neves, 2012). Another research investigated the difference of skin temperature in the abdominal region between obese and normal weight groups, and the correlation between abdominal skin temperature and body fat percentage was 0.545 , while the abdominal skin temperature of obese group was lower than in the normal weight group (Savastano et al., 2009). Similar relationships were shown by Neves et al. who observed that subjects with lower subcutaneous fat layer had a higher skin temperature variation rate during exercise than those with a thicker subcutaneous fat layer (Neves et al., 2015).

The body thermal response varies according to each body region; moreover, it shows significant individual differences, depending on the parameters of body composition. In our previous study on these relationships in people with extremely different body compositions, women with simple obesity (BMI greater than 30 ) had significantly lower mean temperatures on the surface of the abdomen and thighs (i.e. areas with the largest proportion of body fat) than women with normal weight. It is worth noting that the mean temperatures $\left(T_{\text {mean }}\right)$ in those areas in obese women significantly negatively correlated not only with BMI or body fat percentage, but also with the content of subcutaneous fat and the amount of visceral fat (Chudecka, Lubkowska, Kempińska-Podhorecka, 2014).

Our previous study on women diagnosed with anorexia nervosa showed significantly higher temperatures $\left(T_{\text {mean }}\right)$ on the surface of the abdomen, lower back and thighs compared to women with normal weight, while significantly lower temperatures on the surface of hands. The mean surface temperature of the abdomen significantly negatively correlated with BMI, PBF (percentage of body fat), SFM (subcutaneous fat mass) and VFM (visceral fat mass) (Chudecka, Lubkowska, 2016).

This study was first to evaluate temperature changes in certain areas of the body in patients with a precisely defined surgical reduction in subcutaneous fat tissue. Our research can be considered as pioneering and having significant role in the confirmation of subcutaneous fat as a factor regulating the temperature of the body surface. Reduction of subcutaneous tissue in the abdomen caused upward trends in the surface temperature of most of the analyzed areas, with a highly significant increase in the abdominal area $(p=0.0003)$.

Adipose tissue, because of its reduced thermal conductivity and increased insulatory capacity provides an insulating barrier to conductive heat flow and reduces the body's ability to respond to changes in core temperature, which is confirmed by our observations. Our results suggest that the thickness of the subcutaneous fat layer influences the skin temperature at resting. It can be concluded that subcutaneous fat layer acts as a thermal barrier against muscle heat dissipation. 
Interestingly, in the area of upper and lower extremities (hand front and back, thigh front and back) we not only recorded growth trends in surface temperature, but we could only consider them to be downward trends. Our findings suggest that, reduced heat loss related to high abdominal fat is accompanied, under thermoneutral conditions, by augmented heat dissipation from the hands. Furthermore, Savastano et al. found that obese participants had warmer fingernail bed temperatures than the normal weight people (David et al., 2009)

In summary, our results indicate that liposuction removal of abdominal subcutaneous adipose tissue in normal-weight subjects lead to significant increase in abdominal surface temperatures with a slight decrease in the temperature on extremities measured under thermoneutral conditions. This research thus provides additional evidence that body regions of decreased adiposity intensify core-to-skin heat loss and that the heat dissipation from peripheral regions, such as the hands, is blunted.

Some limitations of our study must be noted. First, there was a small number of participants. Second, thermal distributions may also be dependent on physiological differences between participants, such as hydration, stage in menstrual cycle or medication use. Unfortunately, those factors were not taken into account in the present study.

\section{References}

Bandeira, F., Moura, M.A.M., Souza, M.A., Nohama, P., Neves, E.B. (2012). Pode a termografia auxiliar no diagnóstico de lesões musculares em atletas de futebol? Revista Brasileira de Medicina do Esporte, 18 (4), 246-251.

Bauer, J., Dereń, E. (2014). Standaryzacja badań termograficznych w medycynie i fizykoterapii. Inżynieria Biomedyczna, 20 (1), 11-20.

Chudecka, M., Lubkowska, A. (2016). Thermal imaging of body surface temperature distribution in women with anorexia nervosa. European Eating Disorders Review, 24, 57-61. DOI: 10.1002/erv.2388.

Chudecka, M., Lubkowska A., Kempińska-Podhorodecka A. (2014). Body surface temperature distribution in relation to body composition in obese women. Journal of Thermal Biology, 43, 1-6. DOI: 10.1016/j.jtherbio.2014.03.001.

Drozdowski, Z. (1998). Antropometria w wychowaniu fizycznym. Seria: Monografie. Poznań: AWF.

Fujimasa, I. (1995). Standardization of techniques for thermal imaging testing: the current situation. Part 1. Basic Information. Biomedical Thermology, 15, 63-68.

Matarasso, A., Hutchinson, O.H. (2001). Liposuction. JAMA, 285, 266-268.

Matarasso, A., Kim, R.W., Kral, J.G. (1988).The impact of liposuction on body fat. Plast Reconstr Surg, 102 (5), $1686-1689$.

Neves, E.B., Moreira, T.R., Lemos, R.J., Vilaça-Alves, J., Rosa, C., Reis, V.M. (2015). The influence of subcutaneous fat in the skin temperature variation rate during exercise. Res. Biomed. Eng, 31 (4), 307-312.

Savastano, D.M., Gorbach, A.M., Eden, H.S., Brady, S.M., Reynolds, J.C., Yanovski, J.A. (2009).Adiposity and human regional body temperature. Am J Clin Nutr, 90, 1124-1131.

Simka, M. (2007). Liposuction and diabetes type 2 development risk reduction. Med. Hypotheses, 69, 958-959.

The American Society for Aesthetic Plastic Surgery (2002). Cosmetic Surgery National Data Bank Statistics retrieved from: http://www. surgery.org/press/statistics-2002.asp.

Unger, R.H. (2003). Minireview: Weapons of lean body mass destruction: the role of ectopic lipids in the metabolic syndrome. EnEndocrinology, 144, 5159-5165.

Żuber J., Jung, A. (1997). Thermographic methods in medical diagnosis. Bomar Marketing. Warszawa.

Cite this article aS: Chudecka, M., Dmytrzak, A., Lubkowska, A. (2016). Changes in Selected Morphological Parameters and Body Composition, as well as Mean Body Surface Temperature Assessed by Thermal Imaging, in Women after Abdominal Liposuction. Central European Journal of Sport Sciences and Medicine, 14 (2), 21-26. DOI: 10.18276/cej.2016.2-03. 